\title{
“Conditional Conditioning" in cardiac bypass surgery
}

\author{
Derek J. Hausenloy • Derek M. Yellon
}

Received: 24 February 2012/ Accepted: 27 February 2012/Published online: 18 March 2012

(C) Springer-Verlag 2012

Coronary artery bypass graft (CABG) surgery remains the procedure of choice for coronary artery revascularization in patients with multi-vessel coronary artery disease (CAD). For patients undergoing elective isolated CABG surgery, clinical outcomes are very good $(1.5 \%$ in-hospital mortality in the UK) [35]. However, increasing numbers of higher risk patients are being operated, resulting in higher in-hospital mortality rates. The reasons for this increase in high risk patients include: patients being older $(25 \%$ of all cardiac surgery in the UK is in patients over 75 years of age); the increasing prevalence of co-morbidities such as diabetes (33\% increase since 2001 and in-hospital mortality of $1.9 \%$ ), left ventricular impairment (in-hospital mortality is $6.8 \%$ in patients with poor left ventricular systolic function), extra-cardiac arteriopathy (in-hospital mortality of $2.9 \%$ ), renal impairment (in-hospital mortality of $8.9 \%$ ), previous myocardial infarction (doubles in-hospital mortality) and valvular disease (in-hospital mortality is $3.5 \%$ for valve only surgery and $6.1 \%$ for combined valve and graft operations) [35].

High risk patients undergoing cardiac bypass surgery are particularly susceptible to peri-operative myocardial injury (PMI). The presence of this form of myocardial injury, which can be detected and quantified by the release of cardiac-specific biomarkers such as CK-MB, troponin T or I, has been associated with worse clinical outcomes [6, 25]. PMI is attributable to a number of different factors including

This invited editorial is related to the original contribution available at doi:10.1007/s00395-012-0256-6; a second invited editorial to this article can be found at doi:10.1007/s00395-012-0259-3.

D. J. Hausenloy · D. M. Yellon ( $₫)$

The Hatter Cardiovascular Institute, University College London, 67 Chenies Mews, London WC1E 6HX, UK

e-mail: d.yellon@ucl.ac.uk acute global myocardial ischemia-reperfusion injury (due to aortic cross clamping and unclamping), distal coronary micro-embolization [15], direct myocardial injury from manual handling of the heart, and systemic inflammatory injury from cardiopulmonary bypass [11].

One potential therapeutic strategy for protecting the myocardium against the acute ischemia-reperfusion injury (IRI) component of PMI is "Remote Ischaemic Preconditioning" (RIPC) [31]. This describes the endogenous cardioprotective phenomenon, in which the application of one or more cycles of brief non-lethal ischemia and reperfusion to an organ (such as the kidney, liver or small intestine) $[8,29]$ or tissue (such as the skeletal muscle of the upper or lower limb) [2, 28], protect the heart against a sustained episode of acute lethal IRI [14]. The practical transition of this cardioprotective phenomenon to the clinical setting was made possible with the discovery by Kharbanda et al. [22] that the effect of RIPC could be recapitulated in human volunteers by simply inflating and deflating a blood pressure cuff, placed on the upper arm to induce brief episodes of non-lethal ischemia and reperfusion in the forearm.

The clinical application of RIPC was first successfully demonstrated by Cheung et al. [4], who reported that, in children undergoing corrective cardiac bypass surgery for congenital heart disease, RIPC (comprising four 5-min cycles of inflation and deflation of a cuff placed on the thigh) reduced post-operative peak levels of troponin-I, lowered airway pressures and reduced inotrope requirements, when compared to control. A year later, Yellon's group found that RIPC (comprising three 5-min cycles of inflation and deflation of a cuff placed on the upper arm) reduced the extent of PMI (as evidenced by a $43 \%$ reduction in $72 \mathrm{~h}$ area under the curve serum troponin-T) in adult patients undergoing elective $\mathrm{CABG}$ surgery when 
compared to control [13]. A number of subsequent clinical studies have confirmed the beneficial effects of RIPC in the setting of cardiac bypass surgery as well as elective [17, 18] and primary percutaneous coronary intervention [3, 33], but not all of these studies have been positive (see Table 1).

In this issue of Basic Research in Cardiology, Young et al. [42] report a study which failed to find any beneficial effects with RIPC in 96 patients undergoing high risk CABG surgery. In this study, high risk surgery was defined as double valve or triple valve surgery, mitral valve surgery, CABG plus valve(s) surgery, CABG in patients with LV impairment or any 're-do' operation [42]. Somewhat surprisingly, they found a greater degree of PMI in those patients which had been randomized to receive RIPC, when compared to control, as indicated by higher peak levels of high-sensitive troponin- $\mathrm{T}$ at 6 and $12 \mathrm{~h}$. A potential explanation for this alarming finding may be due to the fact that all the patients undergoing the most complex form of surgery, i.e. triple valve surgery or CABG with double valve surgery, were in the RIPC-treated group. This unequal distribution may also explain the longer cross clamp times observed in the RIPC-treated group compared to the control (117 vs. $105 \mathrm{~min}$ ). Furthermore, a more accurate estimate of PMI would have been obtained in this study with serial sampling over the 72 -h peri-operative period in order to calculate an area under the curve highsensitive troponin-T. All things considered, the current study by Young et al. [42] is now the third to report negative results with RIPC in patients undergoing cardiac bypass surgery (see Table 1), raising some doubts over the efficacy of this phenomenon in this clinical setting.

The mixed results of the RIPC studies might suggest that the cardioprotection elicited by currently used RIPC protocols (three 5-min cycles of inflation and deflation of a cuff placed on the upper arm or thigh) may not be effective in all patient populations and appears to be highly dependent on the conditions of surgery [12]. Close examination of the major clinical studies investigating RIPC in adults undergoing cardiac bypass surgery reveals important differences between the studies, some of which may in part, explain the discordant findings (see Table 1) [30].

To begin with, the patient population which is most likely to benefit from RIPC during cardiac bypass surgery is unknown. The majority of clinical studies have investigated patients with stable coronary artery disease undergoing CABG surgery alone. However in the negative study by Rahman et al. [32], half of the patients had unstable coronary artery disease, having been admitted with an acute coronary syndrome. Whether the inclusion of these patients can explain the lack of efficacy of RIPC in this clinical study is unknown, although patients with chest pain in the preceding $48 \mathrm{~h}$ had been excluded from the study [32].
Most of the studies suggest that patients undergoing valve surgery either alone or in combination with CABG are also amenable to RIPC cardioprotection (see Table 1).

With respect to the RIPC stimulus itself, virtually no work has actually been undertaken to characterize the most effective RIPC protocol in the setting of cardiac bypass surgery. The majority of clinical studies have used the original RIPC protocol first described by Kharbanda et al. [22] comprising three 5-min inflations and deflations of a cuff placed on the upper arm to induce cycles of brief nonlethal ischaemia and reperfusion in the skeletal tissue and skin of the forearm. Whether this is the optimum protocol with respect to the number of cycles, the duration of individual preconditioning episodes of ischemia and reperfusion, and the choice of arm or leg, remains to be determined. It may well be that under specific conditions the standard RIPC protocol may be ineffective, and the protective stimulus needs to be augmented by increasing the RIPC protocol to 4 cycles of ischemia and reperfusion, or even using simultaneous arm and leg cuff inflations [39]. Another factor to take into consideration is the timing of the RIPC stimulus, which should be delivered within $2-3 \mathrm{~h}$ of the index episode of acute ischaemia (aortic cross clamping) and reperfusion (aortic unclamping) injury, to be effective. The majority of the RIPC studies have administered the protective stimulus after the induction of anesthesia and prior to the first surgical incision (see Table 1). However, in two of the negative RIPC studies [32, 42], the protective protocol was initiated after the first surgical incision, but prior to cardiopulmonary bypass. Whether the efficacy of the RIPC stimulus was affected by it being delivered at the time of the surgical incision is unknown. In recent experimental studies, it has been reported that a surgical incision may be sufficient in itself to induce cardioprotection in animal models of acute IRI, a phenomenon which has been termed 'remote preconditioning of trauma' $[9,19]$. Interestingly, $\mathrm{Li}$ et al. [26] found that in patients undergoing valve surgery, RIPerC with the protective stimulus applied immediately following aortic cross clamping (i.e. after the onset of acute global myocardial ischaemia) was more effective than administering RIPC, after anesthesia induction and prior to aortic cross clamp. This is the first RIPC study to apply a protective stimulus after the onset of aortic cross clamping and from the data it appears to be more effective than RIPC, at least in this patient population.

The reason for delay in the administration of RIPC until after surgical incision in the studies by Rahman et al. [32] and Young et al. [42] was to allow for the execution of a more robust sham RIPC protocol, which required the inflation of a cuff placed on a 'dummy' arm (using either a wooden cylinder or towel) concealed beneath the surgical drapes [32, 42]. The elaborate design of the sham RIPC 


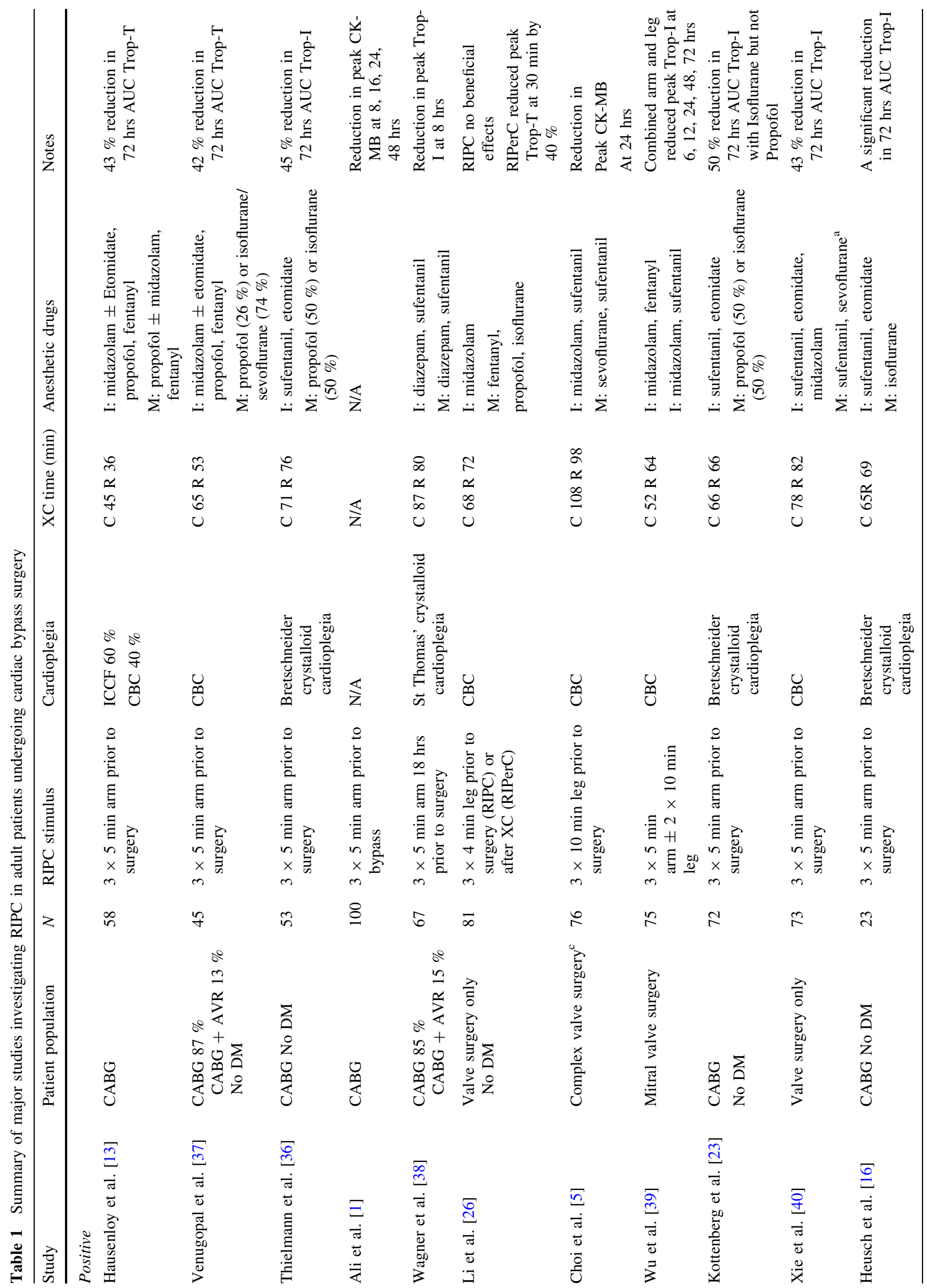




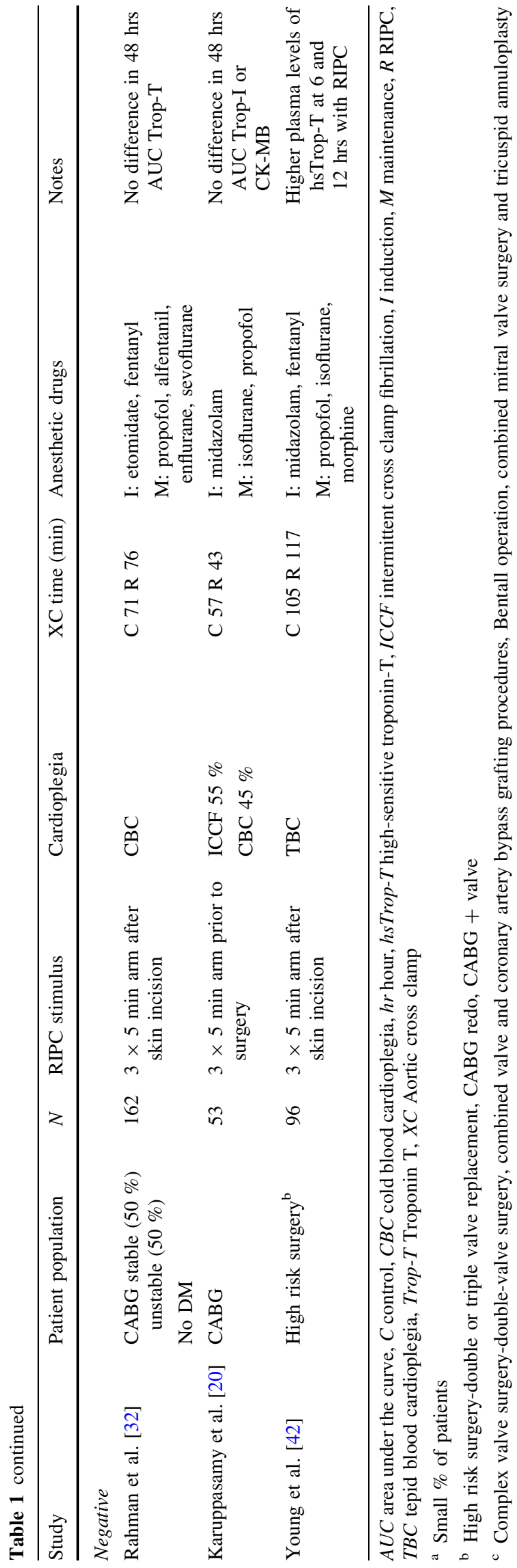

protocol used by Rahman et al. [32] and Young et al. [42] was undertaken to ensure the treatment allocation remains concealed. This precaution was overlooked in most of the other studies, with the use of an inferior sham RIPC protocol, comprising a deflated cuff placed on the upper arm.

Whether the type of myocardial preservation strategy has any influence on the efficacy of RIPC during cardiac bypass surgery is unknown. The majority of clinical studies have used cold blood cardioplegia, although a few have also utilized crystalloid cardioplegia or intermittent cross-clamp fibrillation (ICCF). The fact that all three negative RIPC studies were also performed using cold or tepid blood cardioplegia and in one case ICCF suggests that the myocardial preservation strategy may not influence the efficacy of RIPC protection.

The choice of anesthetic regimen used in the clinical study may be critical to the outcome of the RIPC study [30]. It is well established in the experimental literature that inhaled anesthetic agents (such as isoflurane, sevoflurane, desflurane and enflurane) confer powerful cardioprotection in animal models of acute IRI [7, 11, 21]. A number of meta-analyses have suggested beneficial effects with inhaled anesthetic agents when compared to intravenous anesthetic agents in patients undergoing cardiopulmonary bypass surgery, in terms of less PMI and possibly improved clinical outcomes [24, 34, 43]. There are also experimental and clinical data to suggest that the intravenous anesthetic agent, propofol, is cardioprotective in animal models of IRI [27], and during cardiac bypass surgery [41].

On this background, it is interesting to note that in the three negative RIPC studies (Table 1), all patients received a combination of inhaled anesthetic agents and propofol to maintain anesthesia during cardiac bypass surgery. In contrast, in the majority of the positive RIPC studies (Table 1), these anesthetic agents were either not given at all or if they were, they were not given in combination. This would suggest that when inhaled anesthetic agents (such as isoflurane, sevoflurane or enflurane) and propofol are used in combination to maintain anesthesia during cardiac bypass surgery, RIPC using the standard protocol (three 5-min cycles of inflation and deflation of a cuff placed on the upper arm), may be ineffective. Of interest, the study by $\mathrm{Li}$ et al. [26] also failed to show cardioprotection with RIPC in patients undergoing valve surgery using maintenance anesthesia with propofol in combination with isoflurane. However, in that study it was shown that RIPerC in the protective protocol delivered after aortic cross clamp was still able to reduce PMI in the presence of these anesthetic agents. The one clinical study which directly compared the individual effects of propofol versus isoflurane on RIPC cardioprotection, demonstrated a reduction in PMI in those patients receiving isoflurane but 
not propofol, suggesting that in this study propofol abrogated the cardioprotective effects of RIPC [23]. The mechanism through which the anesthetic agents blunt RIPC protection is unclear. Is the lack of RIPC efficacy due to the fact that patients are already cardioprotected by these anesthetic agents? An analysis of the troponin-I release curves in the study by Kottenberg et al. [23] shows no difference in magnitude of PMI in the control groups whether propofol or isoflurane was administered, suggesting that in this study, propofol was actually abrogating RIPC protection.

In summary, the study by Young et al. [42] adds to the growing research literature that the cardioprotection elicited by current RIPC protocols is highly dependent on the conditions of surgery. In this regard, we believe the overriding factor appears to be the choice of anesthetic agent which is used to maintain anesthesia during surgery. All three negative RIPC studies employed the use of inhaled anesthetic agents (isoflurane, sevoflurane or enflurane) in combination with the intravenous anesthetic agent, propofol. Whether a stronger RIPC stimulus (either more cycles or simultaneous arm and leg cuff inflation) would be effective in this setting remains to be determined. Importantly, the results of two large multi-center randomized controlled clinical trials (ERICCA [10] and RIPHeart: NCT01067703), which have both been designed to investigate the effect of RIPC on clinical outcomes in patients undergoing cardiac bypass surgery, should let us know whether RIPC will be part of the cardiac surgeons' future armamentarium or whether RIPC will be consigned to the surgical waste bin of history!

\section{References}

1. Ali N, Rizwi F, Iqbal A, Rashid A (2010) Induced remote ischemic pre-conditioning on ischemia-reperfusion injury in patients undergoing coronary artery bypass. J Coll Phys Surg Pak 20:427-431. doi:07.2010/JCPSP.427431

2. Birnbaum Y, Hale SL, Kloner RA (1997) Ischemic preconditioning at a distance: reduction of myocardial infarct size by partial reduction of blood supply combined with rapid stimulation of the gastrocnemius muscle in the rabbit. Circulation 96:16411646

3. Botker HE, Kharbanda R, Schmidt MR, Bottcher M, Kaltoft AK, Terkelsen CJ, Munk K, Andersen NH, Hansen TM, Trautner S, Lassen JF, Christiansen EH, Krusell LR, Kristensen SD, Thuesen L, Nielsen SS, Rehling M, Sorensen HT, Redington AN, Nielsen TT (2010) Remote ischaemic conditioning before hospital admission, as a complement to angioplasty, and effect on myocardial salvage in patients with acute myocardial infarction: a randomised trial. Lancet 375:727-734. doi:10.1016/S0140-6736 (09)62001-8

4. Cheung MM, Kharbanda RK, Konstantinov IE, Shimizu M, Frndova H, Li J, Holtby HM, Cox PN, Smallhorn JF, Van Arsdell GS, Redington AN (2006) Randomized controlled trial of the effects of remote ischemic preconditioning on children undergoing cardiac surgery: first clinical application in humans. J Am Coll Cardiol 47:2277-2282. doi:10.1016/j.jacc.2006.01.066

5. Choi YS, Shim JK, Kim JC, Kang KS, Seo YH, Ahn KR, Kwak YL (2011) Effect of remote ischemic preconditioning on renal dysfunction after complex valvular heart surgery: a randomized controlled trial. J Thorac Cardiovasc Surg 142:148-154. doi: 10.1016/j.jtcvs.2010.11.018

6. Croal BL, Hillis GS, Gibson PH, Fazal MT, El Shafei H, Gibson G, Jeffrey RR, Buchan KG, West D, Cuthbertson BH (2006) Relationship between postoperative cardiac troponin I levels and outcome of cardiac surgery. Circulation 114:1468-1475. doi: 10.1161/CIRCULATIONAHA.105.602370

7. Freedman BM, Hamm DP, Everson CT, Wechsler AS, Christian CM (1985) Enflurane enhances postischemic functional recovery in the isolated rat heart. Anesthesiology 62:29-33

8. Gho BC, Schoemaker RG, van den Doel MA, Duncker DJ, Verdouw PD (1996) Myocardial protection by brief ischemia in noncardiac tissue. Circulation 94:2193-2200

9. Gross GJ, Baker JE, Moore J, Falck JR, Nithipatikom K (2011) Abdominal surgical incision induces remote preconditioning of trauma (RPCT) via activation of bradykinin receptors (BK2R) and the cytochrome P450 epoxygenase pathway in canine hearts. Cardiovasc Drugs Ther 25:517-522. doi:10.1007/s10557-0116321-9

10. Hausenloy DJ, Candilio L, Laing C, Kunst G, Pepper J, Kolvekar S, Evans R, Knight R, Ariti C, Clayton T, and Yellon DM (2012) Effect of remote ischemic preconditioning on clinical outcomes in patients undergoing coronary artery bypass graft surgery (ERICCA): rationale and study design of a multi-centre randomized double-blinded controlled clinical trial. Clin Cardiol (Epub ahead of print)

11. Hausenloy DJ, Yellon DM (2012) Cardioprotection during cardiac surgery. Cardiovasc Res (in press)

12. Hausenloy DJ, Baxter G, Bell R, Botker HE, Davidson SM, Downey J, Heusch G, Kitakaze M, Lecour S, Mentzer R, Mocanu MM, Ovize M, Schulz R, Shannon R, Walker M, Walkinshaw G, Yellon DM (2010) Translating novel strategies for cardioprotection: the Hatter workshop recommendations. Basic Res Cardiol 105:677-686. doi:10.1007/s00395-010-0121-4

13. Hausenloy DJ, Mwamure PK, Venugopal V, Harris J, Barnard M, Grundy E, Ashley E, Vichare S, Di Salvo C, Kolvekar S, Hayward M, Keogh B, MacAllister RJ, Yellon DM (2007) Effect of remote ischaemic preconditioning on myocardial injury in patients undergoing coronary artery bypass graft surgery: a randomised controlled trial. Lancet 370:575-579. doi:10.1016/ S0140-6736(07)61296-3

14. Hausenloy DJ, Yellon DM (2008) Remote ischaemic preconditioning: underlying mechanisms and clinical application. Cardiovasc Res 79:377-386. doi:10.1093/cvr/cvn114

15. Heusch G, Kleinbongard P, Bose D, Levkau B, Haude M, Schulz R, Erbel R (2009) Coronary microembolization: from bedside to bench and back to bedside. Circulation 120:1822-1836. doi: 10.1161/CIRCULATIONAHA.109.888784

16. Heusch G, Musiolik J, Kottenberg E, Peters J, Jakob H, Thielmann M (2012) STAT5 activation and cardioprotection by remote ischemic preconditioning in humans: short communication. Circ Res 110:111-115. doi:10.1161/CIRCRESAHA.111.259556

17. Hoole SP, Heck PM, Sharples L, Khan SN, Duehmke R, Densem CG, Clarke SC, Shapiro LM, Schofield PM, O'Sullivan M, Dutka DP (2009) Cardiac remote ischemic preconditioning in coronary stenting (CRISP Stent) study: a prospective, randomized control trial. Circulation 119:820-827. doi:10.1161/CIRCULATIONAHA. 108.809723

18. Iliodromitis EK, Kyrzopoulos S, Paraskevaidis IA, Kolocassides KG, Adamopoulos S, Karavolias G, Kremastinos DT (2006) 
Increased $\mathrm{C}$ reactive protein and cardiac enzyme levels after coronary stent implantation. Is there protection by remote ischaemic preconditioning? Heart 92:1821-1826. doi:10.1136/ hrt.2006.089060

19. Jones WK, Fan GC, Liao S, Zhang JM, Wang Y, Weintraub NL, Kranias EG, Schultz JE, Lorenz J, Ren X (2009) Peripheral nociception associated with surgical incision elicits remote nonischemic cardioprotection via neurogenic activation of protein kinase C signaling. Circulation 120:S1-S9. doi:10.1161/ CIRCULATIONAHA.108.843938

20. Karuppasamy P, Chaubey S, Dew T, Musto R, Sherwood R, Desai J, John L, Shah AM, Marber MS, Kunst G (2011) Remote intermittent ischemia before coronary artery bypass graft surgery: a strategy to reduce injury and inflammation? Basic Res Cardiol 106:511-519. doi:10.1007/s00395-011-0185-9

21. Kato R, Foex P (2002) Myocardial protection by anesthetic agents against ischemia-reperfusion injury: an update for anesthesiologists. Can J Anaesth 49:777-791. doi:10.1007/BF0301 7409

22. Kharbanda RK, Mortensen UM, White PA, Kristiansen SB, Schmidt MR, Hoschtitzky JA, Vogel M, Sorensen K, Redington AN, MacAllister R (2002) Transient limb ischemia induces remote ischemic preconditioning in vivo. Circulation 106: 2881-2883

23. Kottenberg E, Thielmann M, Bergmann L, Heine T, Jakob H, Heusch G, Peters J (2012) Protection by remote ischemic preconditioning during coronary artery bypass graft surgery with isoflurane but not propofol-a clinical trial. Acta Anaesthesiol Scand 56:30-38. doi:10.1111/j.1399-6576.2011.02585.x

24. Landoni G, Biondi-Zoccai GG, Zangrillo A, Bignami E, D'Avolio S, Marchetti C, Calabro MG, Fochi O, Guarracino F, Tritapepe L, De Hert S, Torri G (2007) Desflurane and sevoflurane in cardiac surgery: a meta-analysis of randomized clinical trials. J Cardiothorac Vasc Anesth 21:502-511. doi:10.1053/ j.jvca.2007.02.013

25. Lehrke S, Steen H, Sievers HH, Peters H, Opitz A, MullerBardorff M, Wiegand UK, Katus HA, Giannitsis E (2004) Cardiac troponin $\mathrm{T}$ for prediction of short- and long-term morbidity and mortality after elective open heart surgery. Clin Chem 50:1560-1567. doi:10.1373/clinchem.2004.031468

26. Li L, Luo W, Huang L, Zhang W, Gao Y, Jiang H, Zhang C, Long L, Chen S (2010) Remote perconditioning reduces myocardial injury in adult valve replacement: a randomized controlled trial. J Surg Res 164:e21-e26. doi:10.1016/j.jss.2010. 06.016

27. Lim KH, Halestrap AP, Angelini GD, Suleiman MS (2005) Propofol is cardioprotective in a clinically relevant model of normothermic blood cardioplegic arrest and cardiopulmonary bypass. Exp Biol Med (Maywood) 230:413-420

28. Oxman T, Arad M, Klein R, Avazov N, Rabinowitz B (1997) Limb ischemia preconditions the heart against reperfusion tachyarrhythmia. Am J Physiol 273:H1707-H1712

29. Pell TJ, Baxter GF, Yellon DM, Drew GM (1998) Renal ischemia preconditions myocardium: role of adenosine receptors and ATPsensitive potassium channels. Am J Physiol 275:H1542-H1547

30. Peters J (2011) Remote ischaemic preconditioning of the heart: remote questions, remote importance, or remote preconditions? Basic Res Cardiol 106:507-509. doi:10.1007/s00395-011-0187-7

31. Przyklenk K, Bauer B, Ovize M, Kloner RA, Whittaker P (1993) Regional ischemic 'preconditioning' protects remote virgin myocardium from subsequent sustained coronary occlusion. Circulation 87:893-899

32. Rahman IA, Mascaro JG, Steeds RP, Frenneaux MP, Nightingale $P$, Gosling P, Townsend P, Townend JN, Green D, Bonser RS (2010) Remote ischemic preconditioning in human coronary artery bypass surgery: from promise to disappointment? Circulation 122:S53S59. doi:10.1161/CIRCULATIONAHA.109.926667

33. Rentoukas I, Giannopoulos G, Kaoukis A, Kossyvakis C, Raisakis K, Driva M, Panagopoulou V, Tsarouchas K, Vavetsi S, Pyrgakis V, Deftereos S (2010) Cardioprotective role of remote ischemic periconditioning in primary percutaneous coronary intervention: enhancement by opioid action. JACC Cardiovasc Interv 3:49-55. doi:10.1016/j.jcin.2009.10.015

34. Symons JA, Myles PS (2006) Myocardial protection with volatile anaesthetic agents during coronary artery bypass surgery: a metaanalysis. Br J Anaesth 97:127-136. doi:10.1093/bja/ael149

35. The Society for Cardiothoracic Surgery in Great Britain and Ireland (2008) Sixth national adult cardiac surgical database report

36. Thielmann M, Kottenberg E, Boengler K, Raffelsieper C, Neuhaeuser M, Peters J, Jakob H, Heusch G (2010) Remote ischemic preconditioning reduces myocardial injury after coronary artery bypass surgery with crystalloid cardioplegic arrest. Basic Res Cardiol 105:657-664. doi:10.1007/s00395-010-0104-5

37. Venugopal V, Hausenloy DJ, Ludman A, Di Salvo C, Kolvekar S, Yap J, Lawrence D, Bognolo J, Yellon DM (2009) Remote ischaemic preconditioning reduces myocardial injury in patients undergoing cardiac surgery with cold-blood cardioplegia: a randomised controlled trial. Heart 95:1567-1571. doi:10.1136/hrt. 2008.155770

38. Wagner R, Piler P, Bedanova H, Adamek P, Grodecka L, Freiberger T (2010) Myocardial injury is decreased by late remote ischaemic preconditioning and aggravated by tramadol in patients undergoing cardiac surgery: a randomised controlled trial. Interact Cardiovasc Thorac Surg 11:758-762. doi:10.1510/icvts. 2010.243600

39. Wu Q, Gui P, Wu J, Ding D, Purusram G, Dong N, Yao S (2011) Effect of limb ischemic preconditioning on myocardial injury in patients undergoing mitral valve replacement surgery. A randomized controlled trial. Circ J 75:1885-1889

40. Xie JJ, Liao XL, Chen WG, Huang DD, Chang FJ, Chen W, Luo ZL, Wang ZP, Ou JS (2012) Remote ischaemic preconditioning reduces myocardial injury in patients undergoing heart valve surgery: randomised controlled trial. Heart 98:384-388. doi: 10.1136/heartjnl-2011-300860

41. Yildirim V, Doganci S, Aydin A, Bolcal C, Demirkilic U, Cosar A (2009) Cardioprotective effects of sevoflurane, isoflurane, and propofol in coronary surgery patients: a randomized controlled study. Heart Surg Forum 12:E1-E9. doi:10.1532/HSF98.2008 1137

42. Young PJ, Dalley P, Garden A, Horrocks C, La Flamme A, Mahon B, Miller J, Pilcher J, Weatherall M, Williams J, Young W, Beasley R (2012) A pilot study investigating the effects of remote ischemic preconditioning in high risk cardiac surgery using a randomised controlled double-blind protocol. Basic Res Cardiol 107:256

43. Yu CH, Beattie WS (2006) The effects of volatile anesthetics on cardiac ischemic complications and mortality in CABG: a metaanalysis. Can J Anaesth 53:906-918. doi:10.1007/BF03022834 